\title{
Analysis of Advertising Creativity and Audience Psychology
}

\author{
Liu Bing ${ }^{1, a}$, Pang Ruiqiu 2,b, ${ }^{*}$ \\ ${ }^{1}$ Academy of Fine Arts, Northeast Normal University, Changchun130024, China \\ ${ }^{2}$ School of Geographical Sciences, Northeast Normal University, Changchun130024, China \\ aice8515@163.com, brq56789@yeah.net \\ ${ }^{*}$ Corresponding author
}

Keywords: Creativity, Advertising, Audience, Emotion.

\begin{abstract}
Around the advertising creativity and the audience to carry out research, combing the nature and characteristics of advertising creativity, thinking about the audience's theoretical background, clarifying the audience's emotional appeal, consumer psychology, and national culture. The research shows: advertising creativity is not only a means of marketing, but also a carrier of information transmission. In creativity, we should not only grasp the emotional analysis of creative advertising and audience, but also analyze the consumer psychology of the audience. While catering to the audience's national culture, we should integrate modern consciousness and aesthetic ideas to stimulate the audience's consumption effectively. To promote the sale of products, at the same time, to give advertising creative aesthetic connotations, so that it becomes a national cultural connotations of excellent advertising works.
\end{abstract}

\section{Introduction}

Advertising is a kind of marketing strategy, but also a kind of cultural carrier, in order to meet the information demand, while completing the interaction with the audience. Advertising creative principle is a kind of marketing communication behavior, through a series of activities, for the audience to disseminate information media, change people's attitudes towards commodities, induce the actual action of the audience and then make the advertiser benefit [1].

Advertising creativity is the soul of advertising, designers highlight the characteristics of commodities and the connotation of brands through innovative expression methods [2, 3]. Excellent advertising creativity with bold and novel expression techniques to create a different artistic effect, impact on the audience's sensory system, and arouse the audience's emotional response, memory and desire [4].

Advertising positioning is the premise of advertising creativity. Advertising positioning is to solve "what to do", advertising creativity is to solve "how to do", and the most important is to accurately grasp the psychology of the audience, in order to achieve more effective creation, marketing communication. Business competition is increasingly fierce today, with the improvement of consumer consumption level, commercial advertising needs more creative ideas, arouse the attention of the audience, only more accurately grasp the hearts of the audience, in order to form an excellent advertising creativity.

\section{Analysis of advertising creativity}

\subsection{Analysis of definition and essence of advertising creativity}

Advertising creativity is expressed as: idea \& creative, that is, using creative expression to cater to and guide the audience's emotional appeal and consumer psychology, and then interact with the audience, effective transmission of information, and thus promote the purchasing power of the audience [5]. Advertising creativity includes two parts: advertising appeals and creative connotations, the purpose of creativity is to cater to the psychology of consumers and convey advertising messages. 
The specific implementation steps are: A. early market research, B. collection and analysis of related design elements, C. reorganization of information, D. creative design, E. evaluation and decision. That is to say, according to the advertisement demand, collect the material extensively, sort out the relevant material and data, find the relationship between the materials, find the creative point of the advertisement design, sublimate the creative point, form the effective sales information, analyze and integrate the obtained information, form the design scheme, and further refine it, and improve the design plan and form the final draft.

In advertising creativity, there are the following ways of thinking:

A. Linear thinking, according to the brand sales information directly thinking about the relevant physical properties, or abstract thinking, linking the imagination to emotions, feelings and other emotional creativity.

B. Divergent thinking: from creative points to the surrounding diffusion of thinking, thinking from the point to the line and plane or three-dimensional space.

The standard of creativity is as follows:

A. symbolism, B. simplicity, C. accuracy, D. uniqueness, E. artistry.

\subsection{Analysis of nature and characteristics of advertising creativity}

Advertising can be understood as a purposeful communicative activity. Creativity is the soul and life of advertising design, while highlighting the theme of advertising, it interacts with the audience through creative thinking, it shocks the audience's psychology with its special artistic appeal and manifestation, and causes its psychological transformation.

Advertising creativity can break through the simple information transmission of advertising, endow it with deeper connotation, meet the needs of the market, economy and environment. In the process of information transmission, it can better realize the interaction and communication with the audience by means of relevant media, thus guiding consumers. Splendid advertising creativity can effectively grasp the psychology of the audience so that its memory is deep, unforgettable or amazing shock, to achieve corporate marketing goals.

Advertising creativity is also characterized by the promotion of audience understanding of brand image and brand concept through creativity and innovative methods, to guide the audience to change their brand attitude, and induce their behaviors to satisfy the advertisers' demands, its connotation includes 3 parts:

A. Creative advertising strategy, how to extract information to design and produce more effective advertising, attract the attention of the audience, achieve product sales, guide consumers to buy.

B. Use creative thinking, use unique charm to achieve and sublime advertising appeals.

C. Fully grasp the psychology of the audience, through design and interaction with the audience.

\section{Analysis of relationship between advertising creativity and audience}

\subsection{Analysis of creative advertising and audience emotion}

Advertisements want to directly touch the psychology of the audience, first of all must attract the attention of the audience, that is, through creative points, arouse the attention of the audience, get the psychological recognition of the audience, arouse a certain memory, sense of their own needs, and then consumption, so that advertisers achieve their goals. Every psychological production has a process, but the audience group is the same. Advertising designers capture the emotions of the audience for creative design, with the help of human appeals, to induce the emotional needs of the audience, and then germinate the motivation to buy, to achieve the purchase behavior.

With the promotion of economic level and people's spiritual civilization, people have diversified demands for advertising, especially in today's rapid development and transmission of information, in order to better improve the visibility of enterprises and businesses, it is necessary to effectively use advertising to publicize enterprises and products. How to make their advertising stand out in the competition, attract the interest of the audience, promote their purchase, this is the premise of 
excellent advertising creativity. Excellent advertising creative must correctly grasp the psychology of the audience, rational appeal is that people will pass rational Intuition to the brain, and emotions are irrational, designers can promote the audience's psychological response through the following ways.

A. advertising creativity, visual image and advertising language should address the psychological needs of the audience. Starting from the interests of the audience, grasp the excitement of the audience's needs, think positively, carry out creative design, and then achieve good promotional effect.

B. advertising creativity, increase the added value of advertising. The needs of the audience are not only material, but also spiritual, the two belong to the state of blending, the needs of the audience provide a broad space for advertisement designers. In advertising design, the material attributes of the product are sublimated, and the product is advertised through advertising creativity to increase the psychological added value of the product, so as to meet the audience materially and enhance the audience's spiritual pleasure.

\subsection{Analysis of creative advertising and consumer psychology}

In advertising creativity, the ingenious design of the screen, for the audience to bring visual impact and aesthetic enjoyment, create a beautiful picture, which to a certain extent caters to the audience's consumer psychology. It is very important to grasp and promote the audience's psychology and purchase desire accurately in the sales process. Excellent advertising creativity is closely related to the consumer psychology of the audience. Advertising creativity needs to accurately grasp these consumer psychology of the audience (comparison psychology, seeking beauty psychology, seek fame psychology, psychology of difference, curiosity, psychology of pricing), use artistic expression, carry out innovative design with distinct personality, promote the spiritual interaction between the audience and the product, and then trigger the audience's emotions and thoughts.

The product's propaganda appeal is combined with the audience's inner efficacy, and the creative expression is used to add fresh and unique value, so as to adapt to the audience's psychological appeal. While carrying on the advertisement creativity, it is particularly important to grasp people's herd psychology first and make more reasonable creativity. With the help of creative means to capture the audience's behavior and psychological trends, targeted advertising creativity can effectively achieve advertising appeals; In today's rich material, advertising designers need to use creative means to grasp the emotional factors of the audience, in the economic tide to obtain their own unique advertising status, and then expand their own interests.

\subsection{Analysis of advertising creativity and audience's national culture}

Advertising creativity takes audience as the receiver of information transmission. Advertising creativity needs to cater to the audience's national cultural awareness, the abstract product appeal sublimated into creative thinking with artistic nature, is the bridge and media between advertisers and the audience, is the soul and life of advertising design. The source of advertising creativity is social life, while culture is the source of creativity. Advertising creativity needs to effectively cut into the audience's psychological identity, in order to have a strong vitality, each audience has a unique national culture, excellent advertising creativity contains the corresponding cultural appeal with the audience.

Modern advertising creativity should absorb useful elements from national culture, maintain national cultural characteristics, integrate modern aesthetics and creative ideas, design and produce modern advertising art works with distinctive characteristics and unique ideas. The audience's acceptance of the message conveyed by the advertisement conforms to their own national culture, and integrates the culture with rich connotation into the advertisement creativity, through the creative form, the audience's attention is aroused and the psychological resonance is formed.

Advertising creativity not only needs to convey product information effectively, but also bears the value of art and aesthetic orientation of the audience. Designers should extract creative elements related to products from national culture, sublimate simple advertising creativity to the cultural level, cater to the audience's ideas and cultural concepts. Therefore, excellent advertising creativity should 
be rooted in It is rooted in the distinct national culture, and gets the psychological identification of the audience.

\section{Conclusion}

In modern advertising, the audience's dominant position in advertising creativity is highlighted, and the research on audience's emotional and psychological demands is becoming more and more important. Advertising creativity is not only a means of marketing, but also a carrier of information transmission. Excellent advertising creativity should meet the emotional needs of the audience, and be closely linked with the consumer psychology of the audience. Advertising creativity needs to accurately grasp these consumer psychology of the audience, to meet the material needs of the audience at the same time, to enhance the spiritual pleasure of the audience.

Modern advertising creativity should absorb useful elements from national culture, maintain national cultural characteristics, integrate modern aesthetics and creative ideas, design and produce modern advertising art works with distinctive characteristics and unique ideas. Excellent advertising creativity can only be rooted in distinct national culture, and get the psychological recognition of the audience, so that their own advertising can occupy a place in the tide of information.

\section{Acknowledgement}

The author gratefully thanks the financial support by Fundamental Research Funds for the Central Universities / Youth fund of Northeast Normal University in philosophy and social science projects (2017QT008).

\section{References}

[1] Sara Rosengren, Micael Dahlén, Erik Modig, Think Outside the Ad: Can Advertising Creativity Benefit More Than the Advertiser?, Journal of Advertising, vol.42, pp. 320-330, 2013.

[2] Michael A. Belch, George E. Belch, The Future of Creativity in Advertising, Journal of Promotion Management, vol.19, pp. 395-399, 2013.

[3] David Roca, Bradley Wilson, Andres Barrios, Omar Muñoz-Sánchez, Creativity identity in Colombia: the advertising creatives' perspective, International Journal of Advertising,vol. 36, pp. 831-851, 2017.

[4] Rick T. Wilson, Daniel W. Baack, Brian D. Till, Creativity, attention and the memory for brands: an outdoor advertising field study, International Journal of Advertising, vol. 34, pp. 232-261, 2015.

[5] Vivienne S. Y. Leung, Anna N. N. Hui, A Recent Look: Creative Professionals' Perceptions of Creativity in Hong Kong, Services Marketing Quarterly, vol. 35, pp. 138-154, 2014. 